\title{
Effect of clean indoor air laws on smokers: the clean air module of the SimSmoke computer simulation model
}

\author{
David T Levy, Karen Friend, Eugene Polishchuk
}

\begin{abstract}
Objectives-To develop a simulation model to examine the effects of clean indoor air laws on prevalence rates and smoking attributable deaths.

Methods-Based on empirical and theoretical research, the effects of clean air laws are modelled by type of law. The model considers clean air laws at the state levels between 1993 and 2000, and projects the number of smokers and smoking attributable deaths in the USA under different scenarios from 2000 onward.

Results-The model predicts that comprehensive clean air laws have the potential to reduce substantially the number of smokers and smoking attributable deaths, and these effects are predicted to grow over time. The predicted impact of new worksite laws are reduced when previously implemented private and public worksite restrictions are taken into account.

Conclusions-Clean indoor air laws have the ability to reduce smoking rates substantially and save lives, but their impact is likely to depend on their comprehensiveness and prior private worksite restrictions in place.

(Tobacco Control 2001;10:345-351)
\end{abstract}

Keywords: policy; clean indoor air laws; prevalence rates; smoking attributable deaths

Clean indoor air laws, such as laws against smoking in restaurants and workplaces, are often justified in terms of reducing the harmful effects of second hand smoke on nonsmokers. ${ }^{1}$ They may, however, directly influence the behaviours of smokers themselves. ${ }^{1-3}$ A large empirical literature finds that restrictions on smoking in work and public places have been associated with both decreased consumption and prevalence rates. ${ }^{4}$ They reduce opportunities to smoke and shape smoking behaviour through changes in social norms. Restrictions on smoking are generally a key element in comprehensive tobacco control strategies. $^{5}$

The purpose of this paper is to present a model that predicts the effects of clean indoor air laws on prevalence rates and deaths caused by smoking. We address the effects of clean air laws on different sociodemographic groups, and the role of social norms and reduced opportunities to smoke. In addition, the model is used to trace the impact of laws and of private restrictions that have already been implemented, and the effect of implementing stronger laws than those that presently exist throughout the USA.

\section{Methods}

THE SIMSMOKE MODEL

The clean air module is part of a larger computer simulation model of tobacco control policies, known as SimSmoke. That model predicts future prevalence rates and smoking attributable deaths across the US population and by age, sex, and racial/ethnic group.

Discussed at greater length elsewhere, ${ }^{67}$ SimSmoke begins with the number of smokers, never smokers, and six categories of ex-smokers $(<1,1-2,3-5,6-10,11-15,>15$ years) distinguished by age, sex, and racial/ethnic group in the baseline year 1993. As each cohort moves through time, the population model allows for births and deaths, and the smoking model allows for initiation, cessation, and relapse. A first order discrete Markov process is employed.

Smokers are defined as individuals who have smoked at least 100 cigarettes in their lifetime and are currently smoking. Individuals are classified as never smokers from birth until they initiate smoking or die. Since initiation generally occurs before the age of 25 years, ${ }^{2}$ initiation is modelled to occur until age 25 . Initiation rates at a particular age are measured as the change in prevalence rate between those smoking at one age and those smoking at the previous age. This method insures that the number of smokers equals the number of actual smokers at age 25 , rather than relying on separate, unstable measures of initiation and cessation for those under age 25 .

Ex-smokers are defined as those who have smoked at least 100 cigarettes, and are not currently smoking. The rate at which smokers become ex-smokers depends on the first year quit rate (net of relapse). The first year average quit rate is calculated by the quit rate model with adjusters for the age, sex, and racial/ethnic groups. ${ }^{8}$ Smokers may relapse in future years.

The source of data on prevalence, initiation, and cessation rates by demographic group for those ages 15 and above is the 1992/3 tobacco supplement of the Current Population Survey, ${ }^{9}$ and for those below age 15, the 1993 Teenage Attitudes and Practices Survey. ${ }^{10}$ Relapse rates are based on various sources. ${ }^{11-14}$ Population data are from the 1993 Census of Population, fertility rates are from the US Census vital rate inputs tables, and mortality rates are from the 1993 multiple cause-of-death file. ${ }^{15}$ 
Based on prevalence and cessation rates and on risks of smokers and ex-smokers relative to non-smokers, deaths attributable to smoking are predicted. Excess risk caused by smoking is calculated as the difference between death rates of a smoking category and the death rate of never smokers (where death rates are standardised to preserve the overall population death rate). Excess risk is multiplied by the population of the relevant demographic/ smoking group projected for a particular year to obtain smoking attributable deaths. Deaths are distinguished by age, sex, and smoking groups, based on the Cancer Prevention Study II. ${ }^{16}$

ASSUMPTIONS AND STRUCTURE OF THE CLEAN AIR MODULE

In developing the clean air module, simplifications and estimates were developed with our expert advisers based on: (1) policy relevance, (2) empirical support, and (3) tractability.

Focus on clean air laws

Because SimSmoke is a public policy model, we consider the passage of laws requiring smoking bans. Instead of passing laws, public action may be taken to exhort businesses or homes to impose their own smoking bans voluntarily. We do not consider these public policies, because they are not commonly employed by government or empirically studied.

\section{Laws implemented at the state level}

Since SimSmoke uses US prevalence rates, we examine the policy effects at a national level. We assume, however, that policies are implemented by individual states, which commonly implement most clean air laws and are the subject of most empirical studies. ${ }^{34}$

Categories of clean air laws

The module includes four categories of clean air laws: workplaces, restaurants, schools, and other public places. Worksites are designated as a separate entity because smokers spend many waking hours at their places of employment. Although the number of hours an individual may spend in a restaurant per day or week is small, eating and smoking are often linked, and these laws typically generate much media attention. School clean air policies are included because they reduce opportunities to smoke and affect norms when they are actively publicised and enforced. In the model, they influence those below the age of 18 (for example, college bans are not considered).

"Other public places" denotes public places besides restaurants and schools, and includes shopping malls, retail stores (including grocery stores), enclosed arenas, and public transit. ${ }^{17}{ }^{18}$ Restrictions in government buildings, hospitals and childcare centres are subsumed under workplace laws, and elevators, prisons, and hotels/motels were considered to have limited exposure. Although "other public places" are typically less controversial than restaurant bans, they further limit the places in which a smoker can smoke. In addition, they are often the first laws that states implement. They are classified as a single group rather than as separate sites for simplicity, and because there was little basis to distinguish their effects.

The effect of laws is likely to depend on how broadly they apply. We assume that the laws ban all smoking in the designated area, except for workplace laws. The partial workplace ban disallows smoking in work areas, but allows smoking in some designated common areas.

\section{Publicity and enforcing the law}

Efforts to pass clean air laws are generally accompanied by media publicity and community organisation. Media publicity after the law is enacted may be important in informing and getting business and other establishments to comply with the law and may shape social norms. Active enforcement may also increase the perception that smoking is not condoned and may be necessary to insure compliance with the laws in less politically mobilised communities. ${ }^{3}$ Empirical studies suggest that enforcement and publicity have an impact, ${ }^{19-22}$ but the magnitude could not be ascertained from studies. ${ }^{4}$ Publicity and enforcement are considered part of the policy.

Impact on smoking initiation and cessation Prior studies of smoking restrictions ${ }^{4}$ have found the greatest effects on the amount smoked per smoker within six months, with some tendency for these effects to dissipate over time. Reductions in prevalence rates and increases in quit rates become more pronounced over time. ${ }^{4}$

Like other policy modules in SimSmoke, the effects of each clean air law are developed in terms of the percentage change in prevalence rates from their initial rate. The effects are assumed to occur directly through the prevalence rate, and indirectly through initiation and quit rates. For a particular demographic group, we apply the same percentage effect to each of these rates. The effect on the prevalence rate is applied in equal increments (one third of the total effect) to each of the first three years in which the law is implemented. This represents the immediate cessation that occurs in response to the laws. Decreases in the average amount smoked by those who continue smoking are expected to increase cessation further each year that a law is in effect. ${ }^{23}$ Increases in the one year quit rate each year that the law is in effect lead to further reductions in prevalence after the first three years. Reductions in prevalence during the first three years in which the policy is in effect are sustained through decreases in the initiation rate.

The structure of the model is shown in fig 1 . The number of smokers is decreased directly through reductions in prevalence rates, and indirectly through higher cessation rates and lower initiation rates. As the number of smokers declines, fewer deaths are attributable to smoking.

Effects of policies are independent

Knowledge about the interactive effects of other tobacco control policies, such as media 


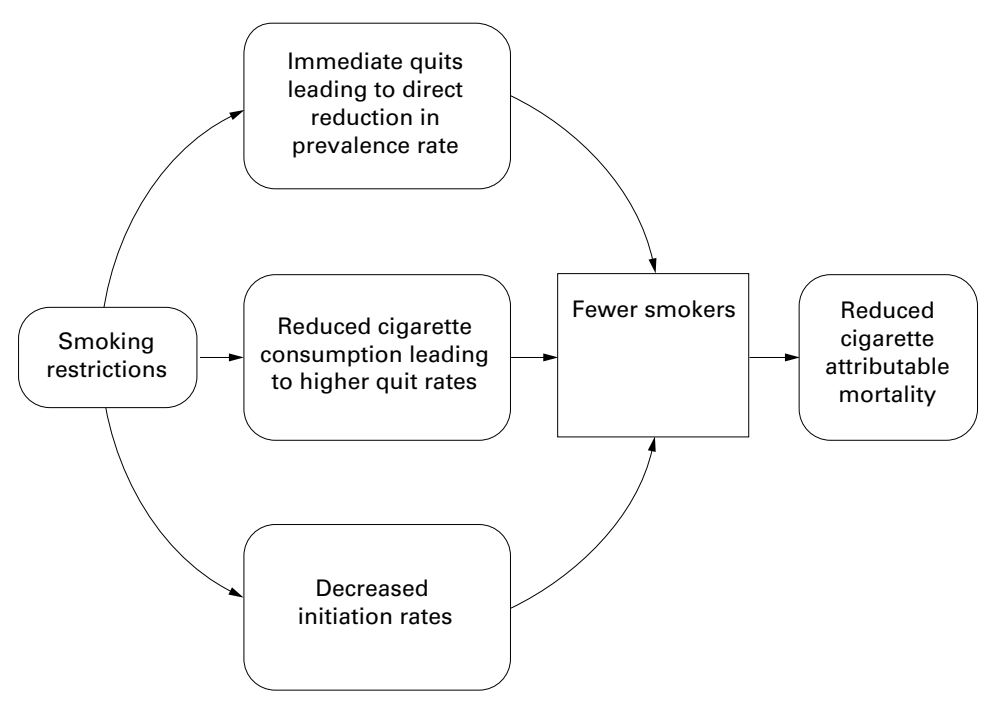

Figure 1 Effects of new smoking restrictions on smoking behaviour and health of smokers.

policies and taxes, with clean air laws is limited. ${ }^{4}$ There may be a synergistic relationship of different policies on social norms and/or smoking behaviours. Alternatively, if other policies (for example, taxes) already reduce smoking opportunities, clean air laws may have less impact. In accordance with other policy modules, we make the neutral assumption that the effects of policies are independent of each other-that is, the effects of clean air laws on prevalence rates are unaffected by other policies in place.

Prior studies also do not explicitly consider interactive effects between each type of clean air law. ${ }^{4}$ While there may be synergistic effects of the laws on social norms, a restaurant law alone may have a greater effect on norms than its incremental impact with a worksite ban already in place. We assume that the effects of different clean air laws are independent.

\section{Health impacts limited to smokers}

Considerable evidence links exposure to smoke with health and even deaths to non-smokers, and this evidence provides a strong justification for the passage of clean air laws. The current version of SimSmoke, however, is limited to considering only the deaths of smokers. The effects of clean air laws on non-smokers will be considered separately when deaths from environmental tobacco smoke are incorporated into SimSmoke.

MAGNITUDE OF EFFECTS

In comparing an extensive law (including worksite, restaurant and other public places) to a minimal clean air law, Emont et $a l^{24}$ and Ohsfeldt $e t a l^{25}$ found $12-14 \%$ reductions in prevalence rates. Chaloupka and Saffer, ${ }^{26}$ Wasserman et $a l^{27}$ and Yurekli and Zhang $^{28}$ found $4-20 \%$ reductions in per capita consumption, which includes changes in quantity smoked by continuing smokers and prevalence, and thus serves as an upper bound. Based on these studies, Levy and Friend ${ }^{4}$ estimate a $10 \%$ reduction in prevalence rates, with a range of $6-14 \%$, as a result of extensive laws within three years after implementation
Prior literature provides limited evidence on the effects of separate clean air laws, except worksite laws. To distinguish the effects, we considered how laws affect social norms and smoking opportunities.

\section{Workplace laws}

Ohsfeldt et $a l^{25}$ found that $60-70 \%$ of the effects of clean air laws were attributable to worksite laws. Using the $10 \%$ reduction for extensive laws, a $6-7 \%$ reduction in prevalence rates was attributable to worksite laws. Both individual worksite and population based studies indicated that workplace restrictions implemented by private entities reduced prevalence rates by $10-20 \%$, with most population based studies finding effects closer to $20 \%{ }^{4}$ Since only $63 \%$ of the adult population worked in $1993^{29}$ and $67 \%$ of workers worked indoors, ${ }^{30}$ the effects would be applied to $42 \%$ (67\% of $63 \%$ ) of the adult population. Thus, the $10-20 \%$ reductions found in studies of workers would imply a $4-8 \%$ reduction for the overall adult smoking population. These results are consistent with the $6-7 \%$ estimate from Ohsfeldt et $a .^{25}$ We estimate a total reduction of a $7 \%$ in the average prevalence rate for the adult population.

A less than a complete ban provides the worker greater opportunity to smoke at work. Farrelly et $a l^{\beta 1}$ and other studies ${ }^{4}$ have found that partial bans had about half or less than half the effect of a complete ban. In addition, partial bans may not be readily enforceable. We estimate that partial bans have one third the impact of a full ban (that is, a $2 \%$ reduction in prevalence rates)

The effects of worksite laws may vary by demographic group, because of different reactions to worksite laws or variations in labour participation rates. Based on labour force participation rates, ${ }^{32}$ prevalence rates in SimSmoke, and results from Farrelly et $a l^{31}$ we multiplied the effect of workplace laws by a factor of 1.06 for whites, Asians, and others and by a factor of 0.65 for African Americans and Hispanics. Farrely et $a \beta^{\beta 1}$ do not find differences in reactions by males and females; female participation rates are on average $80 \%$ that of males and females. We scaled the effect on males by a factor of 1.10 and the effect on females by a factor of 0.91 . Conflicting effects by age group were found by Farrelly et $a l^{\beta 1}$ and by Ohsfeldt et $a .^{25}$ Correcting only for differences in labour participation rates, we scaled the effects of those ages $18-19$ by a factor of 0.9 , those ages $20-25$ by 1.05 , those ages $26-35$ by 1.11 , those ages $36-49$ by 1.10 , those ages $50-59$ by 0.90 , those ages $60-79$ by 0.3 , and those ages $80-89$ by $0 \%$. We estimated that smokers below 18 years of age do not reduce their prevalence rates except through reductions in initiation rates. They are much less likely to work a significant number of hours, but initiation rates are affected through norms and the reduced availability through parents and older peer smokers. 


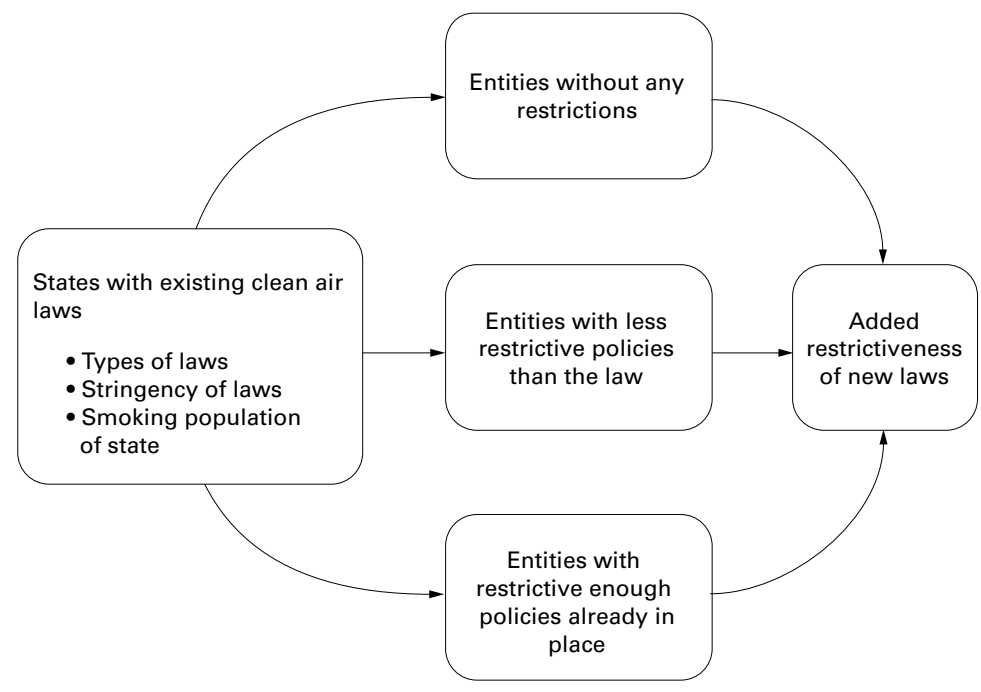

Figure 2 Impact of existing clear air laws and work restrictions.

Restaurant and other public places laws

Based on the estimates that a comprehensive clean air law has a $10 \%$ effect and a worksite law alone has a $7 \%$ effect, a $3 \%$ impact is implied for both restaurants and for other places. The smaller effects are consistent with expectations that smokers generally have much less exposure to these places than worksites. Most of the impact of restaurants and other places is expected to occur through changes in social norms. A restaurant ban sends a message that smoking is not socially acceptable in public. The publicity that often accompanies the passage of these laws is also likely to further impact norms. Because laws pertaining to other places tend to be less controversial to implement, they are expected to have a smaller effect than restaurant bans. A $2 \%$ maximal effect was estimated for restaurant laws and $1 \%$ for other places combined. Because of a lack of evidence or theoretical justification, the effect of public place bans is not distinguished by demographic group.

\section{School laws}

While some studies ${ }^{43}$ found that school policies reduced youth prevalence rates, the magnitude of effects could not be ascertained. ${ }^{4}$ Since all schools had at least classrooms bans through federal and state laws by 1993, prohibitions on smoking in school grounds are expected to have little impact in reducing

Table 1 Percentage change in prevalence rates from clean air laws with no prior policies

\begin{tabular}{lllllllc}
\hline Year & $\begin{array}{l}\text { BAU } \\
(\%)\end{array}$ & $\begin{array}{l}\text { WP } \\
\text { (\% change) }\end{array}$ & $\begin{array}{l}\text { WP partial } \\
\text { (\% change) }\end{array}$ & $\begin{array}{l}\text { Restaurant } \\
\text { (\% change) }\end{array}$ & $\begin{array}{l}\text { Other places } \\
\text { (\% change) }\end{array}$ & $\begin{array}{l}\text { Schools } \\
\text { (\% change) }\end{array}$ & $\begin{array}{l}\text { All policies } \\
\text { (\% change) }\end{array}$ \\
\hline 2000 & 18.5 & -2.3 & -0.7 & -0.7 & -0.3 & 0.0 & -3.3 \\
2001 & 18.4 & -4.2 & -1.4 & -1.2 & -0.6 & -0.1 & -6.1 \\
2002 & 18.3 & -6.0 & -2.0 & -1.8 & -0.9 & -0.1 & -7.1 \\
2003 & 18.2 & -6.0 & -2.0 & -1.8 & -0.9 & -0.1 & -7.2 \\
2004 & 18.1 & -6.0 & -2.0 & -1.8 & -0.9 & -0.1 & -7.4 \\
2005 & 18.0 & -6.1 & -2.1 & -1.8 & -0.9 & -0.1 & -7.5 \\
2010 & 17.6 & -6.3 & -2.1 & -1.9 & -0.9 & -0.2 & -8.1 \\
2015 & 17.1 & -6.6 & -2.2 & -2.0 & -1.0 & -0.2 & -8.7 \\
2020 & 16.6 & -6.7 & -2.3 & -2.1 & -1.0 & -0.3 & -9.2 \\
2025 & 16.0 & -6.9 & -2.4 & -2.2 & -1.1 & -0.3 & -9.7 \\
2030 & 15.5 & -7.1 & -2.4 & -2.3 & -1.1 & -0.4 & -10.1 \\
2035 & 15.2 & -7.2 & -2.5 & -2.3 & -1.1 & -0.4 & -10.5 \\
2040 & 15.0 & -7.3 & -2.5 & -2.3 & -1.1 & -0.5 & -10.8 \\
\hline
\end{tabular}

Percent change $=(\mathrm{BAU}$ prevalence rate - prevalence rate under policy $) / \mathrm{BAU}$ prevalence rate. BAU, business as usual; WP, workplace. opportunities to smoke, especially in the absence of enforcement and penalties for violating the law. Strict school bans might, however, carry a strong message to students that smoking is not acceptable, particularly if the law is backed by enforcement. A complete school ban is estimated to have a $1 \%$ effect on youth prevalence.

\section{EFFECTS OF ALREADY EXISTING LAWS AND} PRIVATE POLICIES

New policies in the model are implemented in the year 2000 and their effects are predicted through to 2040. We consider how the effect of new laws depend on the existence of existing laws and smoking restrictions voluntarily imposed by firms. ${ }^{3}$ The effect of existing laws and private policies are tracked in the model from 1993 through 2000. As shown in fig 2, the laws are differentiated by type and stringency, and are aggregated over the states weighted by the population of smokers in the states. Private work restrictions in the state are distinguished by their stringency relative to the laws in the state.

Using data from the Centers for Disease Control and Prevention (CDC), ${ }^{17} 1834$ states with "no smoking allowed (100\% smoke free)" were counted as $100 \%$ of the effect, with "no smoking allowed or designated smoking areas allowed if separately ventilated" as a $50 \%$ effect, and with "designated smoking areas required or allowed" as a $25 \%$ effect. Because data were not available from the CDC before 1995, we relied on the date of implementation and American Lung Association (ALA) ${ }^{35}$ data for 1993 and 1994. Local laws are from National Cancer Institute (NCI) and are weighted by the local population. ${ }^{3637}$ For school policies, data were only available through the ALA. ${ }^{35}$ A state index was created for each type of law and each year. Because SimSmoke is a national model, the state indices for each type of law were weighted by the state smoking population for each year. ${ }^{38}$

The state representative 1993 and 1996 Current Population Survey tobacco use supplements provided data on the percentage of workers in firms already with private workplace restrictions. ${ }^{39}$ They classified worksites as smoke free, strong (smoking is not allowed in work areas, but in some public areas) and moderate (some or all work areas and some or all public areas). We weighted the latter two categories by 0.5 and 0.25 , respectively, and summed over the three categories. For 1999, data were obtained from the CDC. ${ }^{40}$ We interpolated between years and assumed the same rates in 2000 as in 1999 . For non-worksite laws, we assumed no prior effects of privately imposed restrictions, since much of their effect is through changes in norms as a result of passing the law.

Worksite laws are likely to have less effect on worksites that already have restrictions than those that do not, but may increase anti-smoking sentiment and make it more difficult for workers to switch jobs to work in a firm that allows smoking. We assumed that a new law boosts the effect of a private worksite 
Table 2 Lives saved under clean air policies with no prior policies

\begin{tabular}{llllllll}
\hline Year & $\begin{array}{l}\text { Business } \\
\text { as usual }\end{array}$ & $\begin{array}{l}\text { Total WP, } \\
\text { lives saved }\end{array}$ & $\begin{array}{l}\text { WP partial, } \\
\text { lives saved }\end{array}$ & $\begin{array}{l}\text { Restaurant, } \\
\text { lives saved }\end{array}$ & $\begin{array}{l}\text { Other places, } \\
\text { lives saved }\end{array}$ & $\begin{array}{l}\text { Schools, } \\
\text { lives saved }\end{array}$ & $\begin{array}{l}\text { All policies, } \\
\text { lives saved }\end{array}$ \\
\hline 2000 & 421494 & 0 & 0 & 0 & 0 & 0 & 0 \\
2005 & 440090 & 21124 & 7089 & 6190 & 3107 & 0 & 24251 \\
2010 & 460995 & 24217 & 8136 & 7227 & 3628 & 0 & 28120 \\
2015 & 474987 & 27122 & 9124 & 8221 & 4128 & 0 & 31901 \\
2020 & 494987 & 29893 & 10075 & 9160 & 4602 & 33 & 35658 \\
2025 & 511831 & 32431 & 10954 & 10024 & 5037 & 98 & 39286 \\
2030 & 517068 & 34178 & 11570 & 10626 & 5341 & 172 & 41997 \\
2035 & 504823 & 34741 & 11789 & 10847 & 5443 & 280 & 43318 \\
2040 & 475440 & 34095 & 11602 & 10665 & 5361 & 442 & 43268 \\
\hline
\end{tabular}

Lives saved $=$ business as usual lives lost - lives lost under policy.

WP, workplace.

Table 3 Indices of clean air policies in existence from 1993-2000 in percentage terms

\begin{tabular}{lcccccccc}
\hline & 1993 & 1994 & 1995 & 1996 & 1997 & 1998 & 1999 & 2000 \\
\hline Worksite full & & & & & & & & \\
$\quad$ Private firms & 59.5 & 63.5 & 67.5 & 71.5 & 72.9 & 74.3 & 75.8 & 75.8 \\
$\quad$ Laws & 11.3 & 15.5 & 15.8 & 15.8 & 16.7 & 17.2 & 17.2 & 17.2 \\
$\quad$ Final index & 50.9 & 55.3 & 57.4 & 60.2 & 61.0 & 61.9 & 62.5 & 62.3 \\
Worksite partial & 81.7 & 83.7 & 84.8 & 86.2 & 87.3 & 88.5 & 89.6 & 89.5 \\
Restaurant & 17.2 & 19.0 & 19.5 & 19.7 & 19.9 & 20.8 & 20.8 & 20.8 \\
Other places & 12.8 & 13.1 & 13.5 & 13.5 & 13.0 & 13.7 & 13.7 & 13.7 \\
School & 38.5 & 45.7 & 45.7 & 45.7 & 45.7 & 45.7 & 48.2 & 48.2 \\
\hline
\end{tabular}

Indices are weighted averages of state and local laws multiplied by 100, except for worksite which is a the law index multiplied by a private index of the percent of workers in firms that have total or partial ban smoking bans. See text for details.

policy already in place by $33 \%$. Further adjustments incorporated changes in labour participation rates, which increased by $6 \%$ between 1993 and 2000. We assume that effects of a law are randomly distributed over existing firms independent of their worksite practices. The final index for the worksite laws was obtained by multiplying ( 1 - state laws index) by ( 1 - private worksite ban index) and by the labour participation index.

\section{Results}

EFFECTS OF CLEAN AIR LAWS IN THE ABSENCE OF PRIOR POLICIES

We first examined the effects of clean air laws in the absence of prior laws and restrictions by private firms. These results may be used to gauge the potential effect of the laws.

As shown in table 1 , prevalence rates as a percentage of the total population (including those below age 18) in the absence of new laws are projected to fall from $18.5 \%$ in the year 2000 to $15.0 \%$ in the year 2040. With a smoke-free workplace law alone, prevalence rates fall by slightly more than $2 \%$ relative to its initial rate in the first year of the policy, and about an additional $2 \%$ each of the next two years. The effects continue over time reaching a $7.3 \%$ reduction in prevalence rates by the year 2040 as young adults enter the work force and cessation rates are maintained at higher levels. We suggested above that the range of effects for worksite laws would be $4-8 \%$ within three years, translating to a range of $4.5-9 \%$ reductions in the prevalence rate over longer periods.

When partial workplace laws are implemented (allowing smoking in common, but not work areas), we project that prevalence rates are reduced by about one third that of a complete ban, peaking at $2.5 \%$.

Laws prohibiting smoking in restaurants, schools, and other places show similar patterns, but are predicted to have smaller effects than workplace laws. By the year 2040, a restaurant ban and laws banning smoking in three or more pubic places are, respectively, predicted to yield a $2.3 \%$ and $1.1 \%$ reduction in prevalence rates relative to their initial value.

While laws banning smoking in schools are estimated to reduce prevalence rates of youth by $1 \%$, they are predicted to have smaller effects on the smoking population as a whole. In the first four years, they have less than a $0.1 \%$ effect, but their effects reach $0.5 \%$ by the year 2040 as youth smokers age.

A $7.2 \%$ effect is predicted after the first three years when all laws are simultaneously implemented, and a relative reduction in the prevalence rate of $10.8 \%$ is predicted by 2040 . We suggested above that the range of effects for comprehensive laws lie between $6-14 \%$ within three years, translating to a range of $6.5-15 \%$ reductions in the prevalence rate over longer periods.

As shown in table 2, the number of deaths attributable to smoking in the year 2000 are 421494 and increase to 517068 by the year 2030 and then fall. The effects of clean air laws on death rates build more slowly over time than on prevalence rates. A worksite law is predicted to save over 20000 lives per year within five years and 34095 lives per year by 2040 . Except for the effect of school laws, public area laws lead to slightly slower growth patterns than worksite laws (since the effects are less concentrated on older smokers). Since school laws affect youth, who generally do not die from smoking until they reach age 40 , lives are not saved until the year 2020 and reach about 450 in the year 2040 .

Adding each of the other laws leads to a saving of 43268 lives per year by 2040 . Given a range of reductions of $6-14 \%$ within three years, the range of effects for comprehensive laws is between about 26000-60100 lives saved per year by 2040 .

POLICIES IMPLEMENTED IN 1993-2000

The indices of prior worksite and other clean air policies for the years 1993 through 2000 are shown in table 3 . The index of state workplace laws increases from about $11 \%$ in 1993 to $17 \%$ in 2000 , mostly because of new laws in the states of California, Massachusetts, Maryland, and Washington. The index of private workplace restrictions increases from about $60 \%$ to $75 \%$ between 1993 and 2000. After incorporating labour participation, the combined index of past laws and private practices increases from about $51 \%$ to $62 \%$ between 1993 and 2000 . We estimated that $81 \%$ of the firms had implemented at least partial bans in 1993, with an increase to $90 \%$ by the year 2000. From 1993 to 2000, we estimated an increase in the states with strong restaurant laws from $17 \%$ to $21 \%$, schools from $39 \%$ to $48 \%$, and of other public places from $13 \%$ to $14 \%$.

Table 4 presents the predicted effects of clean air laws after taking into account the effect of current laws and policies and of private workplaces with smoking restrictions. Comparing the business as usual levels of 
Table 4 Percentage change in prevalence rates from clean air laws with prior policies

\begin{tabular}{llllllll}
\hline Year & $\begin{array}{l}\text { BAU } \\
\text { (\%) }\end{array}$ & $\begin{array}{l}\text { Total WP alone } \\
\text { (\% change) }\end{array}$ & $\begin{array}{l}\text { Partial WP } \\
\text { (\% change) }\end{array}$ & $\begin{array}{l}\text { Restaurant } \\
\text { (\% chang) }\end{array}$ & $\begin{array}{l}\text { Other places } \\
\text { (\% change) }\end{array}$ & $\begin{array}{l}\text { Schools } \\
\text { (\% change) }\end{array}$ & $\begin{array}{l}\text { All policies } \\
\text { (\% change) }\end{array}$ \\
\hline 2000 & 18.4 & -0.8 & -0.2 & -0.5 & -0.2 & 0.0 & -1.6 \\
2001 & 18.3 & -1.6 & -0.5 & -0.9 & -0.5 & 0.0 & -3.1 \\
2002 & 18.2 & -2.3 & -0.7 & -1.4 & -0.7 & 0.0 & -4.4 \\
2003 & 18.1 & -2.9 & -1.0 & -1.8 & -1.0 & 0.0 & -5.7 \\
2004 & 18.0 & -2.9 & -0.9 & -1.8 & -0.9 & 0.0 & -5.7 \\
2005 & 17.9 & -2.9 & -1.0 & -1.8 & -1.0 & 0.0 & -5.7 \\
2010 & 17.4 & -2.9 & -1.0 & -1.8 & -1.0 & -0.1 & -5.7 \\
2015 & 17.0 & -2.9 & -1.0 & -1.8 & -1.0 & -0.1 & -5.8 \\
2020 & 16.5 & -2.9 & -1.0 & -1.8 & -1.0 & -0.1 & -5.8 \\
2025 & 16.0 & -2.9 & -1.0 & -1.8 & -1.0 & -0.2 & -5.9 \\
2030 & 15.5 & -2.9 & -1.0 & -1.8 & -1.0 & -0.2 & -6.0 \\
2035 & 15.1 & -2.9 & -1.0 & -1.9 & -1.0 & -0.2 & -6.0 \\
2040 & 14.9 & -2.9 & -1.0 & -1.9 & -1.0 & -0.3 & -6.0 \\
\hline
\end{tabular}

Percent change $=($ BAU prevalence rate - prevalence rate under policy $) /$ BAU prevalence rate. BAU, business as usual; WP, workplace.

prevalence rates in the year 2000 of tables 1 and 3, policies implemented between 1993 and 2000 were only predicted to have reduced relative prevalence rates by $0.5 \%$ in the year 2000 ( $18.5 \%$ relative to $18.4 \%$ ). We predict a total of 2042 lives per year in the year 2000 (not shown in table) are saved as a result of laws implemented between 1993 and 2000, with deaths reduced from 421494 to 419452 .

Implementation of comprehensive laws in the year 2000 is predicted to reduce the prevalence rate by about $5.7 \%$ by the year 2003 and by almost $6 \%$ in 2040 (table 4 ). The effects of a comprehensive law are almost equally distributed between worksite laws and the other laws. The total reduction is just more than half of the $11 \%$ predicted in the absence of any prior restrictions (table 1), because a large percentage of firms already had worksite bans by 2000. Lives saved (not shown) are correspondingly reduced when prior restrictions are taken into account.

\section{Discussion}

The simulation model predicted that comprehensive clean air laws with active enforcement and publicity reduce prevalence rates by $11 \%$ relative to their initial rate in states without prior public and private restrictions. The model predicts that over 20000 lives are saved each year within five years after the laws are implemented.

The predicted effects of a comprehensive law in a state without any prior laws are larger than those predicted from a large scale media campaign or a $\$ 0.50$ tax hike. ${ }^{71}$ Unlike other policies, such as youth access interventions and even taxes, the effects of clean air laws are greatest on those aged 25-50, when work participation is highest. The effects on health are more immediate than other policies, because the number of smoking attributable deaths are greatest at the ages of 45-65 when deaths from smoking are more imminent. ${ }^{42}$

The model predicts that work site laws have the largest effect of the clean air laws and lead to a $7 \%$ reduction in the prevalence rate. Smaller effects are predicted for restaurant, schools, and other public places, with greater uncertainty placed on the estimates. While past studies provide a strong basis for claiming that clean air laws affect smoking behaviours of the

\section{What is already known on this topic}

A large empirical literature finds that restrictions on smoking in private work places have been associated with both decreased consumption and prevalence rates. A separate, smaller literature examines the effect of laws that ban smoking in public places. The effects of the different clean indoor air laws on smoking rates and on smoking attributable deaths, and how the effect of clean air laws depends on restrictions in place by private firms, has received little attention.

\section{What this paper adds}

This paper presents a simulation model that predicts the effects of clean indoor air laws on prevalence rates and smoker deaths caused by smoking. We address the effects of clean indoor air laws on different sociodemographic groups, and the role of social norms and reduced opportunities to smoke. In addition, the model is used to trace the impact of laws and of private restrictions that have already been implemented, and the effect of implementing stronger laws than those that presently exist throughout the USA.

adult smoking population, the ability to determine estimates of the effects of specific types of clean air laws is limited.

Our review of studies suggests that there is uncertainty about the effects of clean air laws. Knowledge of the effects on different sociodemographic groups is also incomplete. In particular, better information is needed on the effects on youth and young adults.

When the effect of laws and private policies already implemented in the USA is taken into account, the effects of newly implemented laws are predicted to be smaller, especially for worksite laws. Unfortunately, past empirical studies of clean air laws do not consider the role of private workplace restrictions that are already in effect, and studies of private restrictions do not consider the effect of clean air laws. Clean air laws are likely to have greater effects on workers in firms that have not previously had clean air restrictions, but even prevalence rates in those firms may be reduced if the laws increase anti-smoking sentiment or make it more difficult for workers to switch jobs to firms without smoking bans. Enforcement and publicity surrounding clean air laws may influence these effects, but have also received little attention in empirical studies.

The model predicts that the effects occur most in the first three years after a new law and then grow at much slower rates in future years. While empirical studies indicated that smoking restrictions first affect the quantity of cigarettes and later lead to cessation, ${ }^{4}$ knowledge about the interaction between reductions in quantity smoked and future quits is lacking. Knowledge about the effects on smoking initiation is also limited. 
The model examines policies at the state level. Local laws may have greater community support, and thus may more strongly reinforce norms. However, laws at a local level may be more easily circumvented by smokers working for an employer or going to a restaurant without smoking restrictions, and are also subject to different enforcement mechanisms. Further information is needed on local as compared to state policies.

Finally, past studies have not considered how the effects of clean air laws depend on other types of tobacco control policies. Because clean air laws reduce secondhand smoke, they may play an important role in garnering support for other policies. Knowledge of the effects of tobacco control policies, alone and in combination, and how they affect different sociodemographic groups, will be important in developing comprehensive strategies to reduce prevalence rates.

The clean air module was developed in close conjunction with a team of advisers, including $\mathrm{L}$ Biener, $\mathrm{F}$ Chaloupka, $M$ Cummings, J DiFranza, W Evans, M Farrelly, and J Forster, who have worked with us in developing the general structure and parameter estimates for this and other policy modules in SimSmoke. We would also like to thank Maria Carmona for her SimSmoke. We would also like to thank Maria Carmona for her
help and guidance, and to the Substance Abuse Mental Health Services Administration for their funding of the SimSmoke model. The authors alone are responsible for the content of the paper.

1 United States Department of Health and Human Services, Reducing tobacco use: a report of the Surgeon General. Atlanta,
Georgia.: United States Department of Health and Georgia.: United States Department of Health and Prevention, National Center for Chronic Disease PrevenPrevention, National Center for Chronic Disease Preven-
tion and Health Promotion, Office on Smoking and tion and Health Promotion, Office on Smoking and Health, 2000. (US

2 United States Department of Education, United States Department of Health and Human Services. Preventing tobacco use among young people: a report of the Surgeon General. Atlanta, Georgia: Department of Health and Human Services, Public Health Service, Centers for Disease Control and Prevention, National Center for Chronic Disease Prevention and Health Promotion, Office on Smoking and Health, 1994. (US Government Printing Office No S/N 017-001-00491-0).

3 Levy DT, Friend K. A Framework for evaluating and improving clean indoor air laws. Fournal of Public Health Management and Practice (In press)

4 Levy DT, Friend K. The effects of clean indoor air laws: what do we know and what do we need to know? Working paper, we know and what do we need to know? Working

5 Centers for Disease Control and Prevention. Best practices for comprehensive tobacco control programs. Atlanta, Georgia: Department of Health and Human Services, Public Departh Service, Centers for Disease Control and PrevenHealth Service, Centers for Disease Control and Preven-
tion, National Center for Chronic Disease Prevention and tion, National Center for Chronic Disease Prevention and Health Promotion, Office on Smoking

6 Levy DT, Cummings KM, Hyland A. The effects of reducgrates: a computer simulation model. Am f Public Health 2000;90:1311-14.

7 Levy DT, Cummings KM, Hyland A. Increasing taxes as a strategy to reduce cigarette use and deaths: results of the SimSmoke computer model. Prev Med 2000;31:279-86.

8 Levy DT, Friend K. The effects of cessation treatments policies: their effects in recent years and predicted future effects, using SimSmoke. Working paper, Pacific Institute for Research and Evaluation, 2000 .

9 Bureau of the Census. Current Population Survey, September 1992, fanuary 1993, May 1993: tobacco use supplement [cus1992, Fanuary 1993, May 1993: tobacco use supplement [cus-
tom order cd-rom]. Washington DC: US Department of tom order cd-rom]. Washington DC: US Department of
Commerce, Bureau of the Census [producer], 1994. Ann Commerce, Bureau of the Census [producer], 1994. Ann Arbor, Michigan: Inter-university Consor

10 National Health Interview Survey 1993. Teenage attitudes and practices supplemental file. (CD-ROM series 10, No 7). Hyattsville, Maryland: National Center for Health Statistics [producer and distributor], 1996.

11 McWhorter WP, Boyd GM, Mattson ME. Predictors of quitting smoking: the NHANES I followup experience. $\mathscr{f}$ Clin Epidemiol 1990;43:1399-405.

12 US Dept of Health and Human Services. Health benefits of smoking cessation: a report of the Surgeon General. Rockville, Maryland: Centers for Disease Control and Prevention, National Center for Chronic Disease Prevention and Health Promotion, Office on Smoking and Health, (DHHS Publication No (CDC) 90-8416), 1990.
13 COMMIT Research Group. I. Cohort results from a four-year community intervention: community intervention trial for smoking cessation (COMMIT) Am f Public Health 1995;85:183-92.

14 Gilpin EA, Pierce JP, Farkas AJ. Duration of smoking abstinence and success in quitting. I Natl Cancer Inst 1997;89:572-6.

151993 Multiple Cause-of-Death File (CD-ROM series 20, No 11). Hyattsville, Maryland: National Center for Health Statistics [producer and distributor], 1997.

16 Thun MJ, Myers DG, Day-Lally C, et al. Age and the exposure-response relationships between cigarette smoking and premature death in Cancer Prevention Study II. In: National Cancer Institute. Changes in cigarette-related disease risks and their implication for prevention and control. Smoking and Tobacco Control Monograph 8. Bethesda, Maryland: National Institutes of Health. 1997:383-475 Maryland: National Institutes

17 Centers for Disease Control and Prevention. State laws on tobacco control-United States, 1995. MMWR Mort Morbid Wkly Rep 1995;44(SS-6):1-28.

18 Centers for Disease Control and Prevention. State laws on tobacco control-United States, 1998. MMWR Mort Morbid Wkly Rep 1999;48(SS03):21-62.

19 Rigotti NA, Bourne D, Rosen A, et al. Workplace compliance with a no-smoking law: a randomized community intervention trial. Am $\mathcal{F}$ Public Health 1992; 82:229-35.

20 Rigotti NA, Stoto MA, Bierer MF, et al. Retail stores' compliance with a city no-smoking law. Am $\mathcal{F}$ Public Health 1993;83:227-32.

21 Rigotti NA, Stoto MA, Schelling TC. Do businesses comply with a no-smoking law? Assessing the self-enforcement approach. Prev Med 1994;23:223-9.

22 Jacobson PD, Wasserman J. Tobacco control laws: implementation and enforcement. Santa Monica California: RAND Corporation, 1997

23 Hughes JR. Reduced smoking: an introduction and review of the evidence. Addiction 2000;95(supp 1):S3-8.

24 Emont SL, Choi WS, Novotny TE, et al. Clean indoor air legislation, taxation and smoking behavior in the United States: an ecological analysis. Tobacco Control 1993;2:1317.

25 Ohsfeldt RL, Boyle RG, Capilouto EI. Tobacco taxes, smoking restrictions and tobacco use. NBER Working Paper No 6486. Cambridge: National Bureau of Economic Research, 1996.

26 Chaloupka FJ, Saffer H. Clean indoor air laws and the demand for cigarettes. Contemporary Policy Issues 1992; 10:72-83.

27 Wasserman J, Manning WG, Newhouse JP, et al. The effects of excise taxes and regulations on cigarette smoking. $\mathcal{F}$ Health Econ 1991;10:43-64.

28 Yurekli AA, Zhang P. The impact of clean indoor-air laws and cigarette smuggling on demand for cigarettes: an empirical model. Health Econ 2000;9:159-70.

29 US Department of Commerce. Statistical Abstract of the United States 1997. Washington DC: US Department of Commerce, 1998.

30 Evans WN, Farrelly MC, Montgomery E. Do workplace smoking bans reduce smoking? Am Econ Review 1999; 89:728-47.

31 Farrelly MC, Evans WN, Sfekas A. The impact of workplace smoking bans: results from a national survey. Tobacco Control 1999;8:272-7.

32 WWW page address: http://stats.bls.gov/emplt981.htm

33 Wakefield MA, Chaloupka FJ, Kaufman NJ, et al. Effect of restrictions on smoking at home, at school and in public places on teenage smoking: cross sectional study. $B M \mathcal{F}$ 2000;725:333-6.

34 WWW page address: http://www.cdc.gov.nccdphp/osh/state/ leg_proc.asp

35 American Lung Association. State Legislated Actions on Tobacco Issues. Washington DC, 1999, 1998, 1997, 1996, 1995, 1993

36 National Cancer Institute. Major local tobacco control ordinances in the United States. Smoking and tobacco control monograph No 3. US Department of Health and Human Services, National Institutes of Health, National Cancer Institute, 1993. (NIH Publication No 93-3532)

37 National Cancer Institute. State and local legislative action to reduce tobacco use smoking and tobacco control monograph No 11. Washington DC: National Institutes of Health, National Cancer Institute, 2000. (NIH Publication Number 00-4804)

38 Burns D, Shanks T, Major J, et al. Restrictions on smoking in the workplace. NCI Monograph (in press).

39 Gerlach KK, Shopland DR, Hartman AM, et al. Workplace smoking policies in the United States: results from a national survey of more than 100000 workers. Tobacco Control 1997;6:199-206.

40 Centers for Disease Control and Prevention. State-specific prevalence of current smoking among adults and the proportion of adults who work in a smoke-free environment. United States, 1999. MMWR Mort Morbid Wkly Rep 2000;49:978-82.

41 Levy D, Friend K. A computer simulation model of mass media interventions directed at tobacco use. Prev Med 2001;32:284-94.

42 Lightwood JM, Glantz SA. Short-term economic and health benefits of smoking cessation: myocardial infarction and stroke. Circulation 1997;96:1089-96. 